\title{
Discussion: Elastic analysis of ground-floor slabs under multiple
} loads

\section{A. A. Abbas, M. N. Pavlović and M. D. Kotsovos}

A. N. Beal, Thomasons, Leeds, UK

(a) Have the authors analysed stresses where a load is positioned astride a joint, or across the intersection of two joints? (The slab stresses in this situation cannot be calculated directly from standard analyses for single loads adjacent to corners or edges because, when a load is astride a joint, the subgrade stress below the part of the load on one side of a joint is affected by the load(s) on the other side of the joint(s).)

(b) Have the authors analysed the effects of a sub-base (a layer of compacted hardcore) between the slab and the subgrade?

(c) Have the authors analysed the effects of reinforcement in the slab?

(d) Have the authors compared results from their analysis with those from the design method proposed in Concrete Society Technical Report 34 (3rd edition), ${ }^{8}$ which is the most recently published design guidance in the UK?

\section{Authors' reply}

The work on ground-floor slabs (GFS) carried out to date by the authors has considered only single (i.e. with free edges) slabs (both plain concrete and reinforced) under various loading conditions, in both the elastic and non-linear ranges, as described in half a dozen publications including the present one. Additional questions related to parameters such as joints, the role of fibres and time-dependent effects, will form part of future research currently being planned.

Although we have not studied the effects of a compacted subbase between slab and subgrade, the method of analysis adopted could easily incorporate such an additional layer.
Allowance has been made for the effect of the reinforcement in our research so far. The ensuing results indicate that, in the elastic range, the slab stresses can be obtained on the assumption that the GFS is a plain-concrete slab since, in this linear range, the steel reinforcement is hardly mobilised (although it serves to control shrinkage and thermal effects). As far as stress analysis is concerned, the steel becomes structurally active only after concrete cracks, namely in the non-linear range (should this stage be ever reached), as described in our recent paper. ${ }^{9}$

Finally, as regards other design documents, we mention at the end of section 2 of our paper that the 1982 document TR550 is the most comprehensive elastic guideline on multiple loads. The latest available document is indeed the Concrete Society Technical Report 34 (3rd edition) but its section on multiple loads (pp. 58-60) is limited to plasticdesign calculations of dual and quadruple loads, while the elastic case with which we are concerned (and, in view of the serviceability requirements, the case of primary interest to designers) consists only of reference to the work of Hetenyi on beams on elastic foundations under line and uniformly distributed loads, but not the three-dimensional case of point loads.

\section{REFERENCE}

9. Abbas A. A., Pavlović M. N. and Kotsovos M. D. Postelastic behaviour of ground-floor slabs. Part 2: Fabricreinforced concrete slabs. Magazine of Concrete Research, 2007, 59, No. 6, 401-411. 